\title{
Os sistemas agroflorestais como alternativa de sustentabilidade em ecossistemas de várzea no Amazonas
}

\author{
Albejamere Pereira de CASTRO ${ }^{1}$, Therezinha de Jesus Pinto FRAXE ${ }^{1}$, Jozane Lima SANTIAGO ${ }^{1}$, Raimundo \\ Barbosa MATOS², Ilzon Castro PINTO 3
}

\begin{abstract}
RESUMO
Os sistemas agroflorestais (SAFs) representam uma alternativa agroecológica de produção, sob regime sustentável, para os agricultores familiares na várzea dos Rios Solimões/Amazonas, principalmente no que se refere ao manejo florestal, à diversidade de produtos e à geração de renda. Diante disso, o objetivo deste trabalho foi compreender as diferentes formas de apropriação e de manejo dos recursos naturais através dos SAFs, nos subsistemas roça, sítio e lagos, como componente para a sustentabilidade dos agricultores familiares da localidade Costa da Terra Nova, município do Careiro da Várzea, Amazonas. O método empregado foi o Estudo de Caso com aplicação de questionários, entrevistas e observação participante. A produção familiar na Costa da Terra Nova é representada pelos SAFs, constituído pelos os subsistemas: roça quintal e lago, que proporcionam produtos tanto para subsistência quanto para comercialização local, e estabelecendo a agricultura como fundamental atividade na localidade. O principal produto para comercialização é obtido das hortaliças cultivadas na época da vazante no subsistema roça nas comunidades São Francisco e Nossa Senhora da Conceição; e do extrativismo pesqueiro no subsistema lago, na época da cheia, principalmente na comunidade São José. A criação de animal se dá no subsistema sítio e é apenas para subsistência, sendo as aves e os suínos os principais animais domésticos criados nas três comunidades. Portanto os SAFs tradicionais, constituídos pelos subsistemas, roça, sitio e lago, são responsáveis pela sustentabilidade socioeconômica da localidade pesquisada, servindo, como alternativa agrícola melhor adaptada às condiçōes locais das áreas de várzea na Amazônia.
\end{abstract}

PALAVRAS-CHAVE: Sistemas agroflorestais, Várzea amazônica, Agricultura familiar

\section{The Agroforestry systems as an alternative of sustainable land use in várzea (floodplain) ecosystems in Amazon State}

\begin{abstract}
The Agroforest Systems (SAF`s) presents an agro ecological alternative of production under sustainable basis for the families farmers, in the várzea (floodplain) of the Solimōes/Amazonas Rivers, especially when it is refereed to the forest management, to the products diversity, and the incomes. This study has objective to understand the different ways of appropriation and management of natural resources through SAFs in the different subsystems as clearing, home garden, and lakes as a sustainability component of families' farmers from Costa da Terra Nova located in the Careiro da Várzea County (Amazon). The methodology used was the case study with the questionnaires applied, interviews and participant observation. The families' production in the Costa da Terra Nova is represented for agroforestry systems accordingly with the subsystem: farm, home garden and lakes that provide products for their subsistence as much as much for local commercialization. The local communities established the agriculture as a fundamental activity. The main product is obtained from the vegetables grown during the receding water period in the field subsystem in the communities São Francisco and Nossa Senhora da Conceição; and the extrativismo fishing boat on subsystem lake in water period, predominant in community São José. The animal raising is used only for self-subsistence, being the birds and the pigs the mainly domestic animals raising in the three communities. Thus, the traditional agroforestry systems combined with the forest subsystem, clearing, home garden, and lakes are responsible for social-economics sustainability for the studied area, and could be used as an alternative agriculture better adapted for the local conditions at the Amazonian floodplain areas.
\end{abstract}

KEY WORDS: Agroforest systems, Amazonian floodplain, Family agriculture

\footnotetext{
1 Universidade Federal do Amazonas, Faculdade de Ciências Agrárias

2 Instituto de Pesquisa da Amazônia

${ }^{3}$ Escola Agrotécnica Federal de São Gabriel da Cachoeira-Am.
} 


\section{INTRODUÇÃO}

$\mathrm{Na}$ Amazônia, a agricultura familiar é desenvolvida dentro dos Sistemas Agroflorestais (SAFs), que foram e são implantados por comunidades indígenas, caboclas e ribeirinhas. Os SAFs, foram resgatados de culturas antigas e atualizados para atender às necessidades de evolução no uso da terra, especialmente em regiōes tropicais; hoje se expandem por praticamente todas as regiōes onde sejam possíveis os cultivos agrícolas e florestais (Daniel et al., 1999). Característica importante dos SAFs é a utilização de uma grande diversidade de plantas, manejadas para atender às necessidades vitais da comunidade, isto é, alimentação, saúde (uso de plantas medicinais), confecção de vestuário, construção de casas e abrigos, assim como manufatura de diversos objetos de uso comum, que incluem sistemas indígenas, cultivo itinerante ou migratório, sistemas tradicionais abertos ao mercado e intercultivo de plantas perenes arbóreas, arbustivas e palmáceas (Embrapa - CPAA, 1992).

A utilização de SAFs tem sido, nas últimas décadas, bastante difundida como alternativa para recuperação de áreas degradadas. A combinação de espécies arbóreas com culturas agrícolas e a criação de animais, proporciona a melhoria nas propriedades físico-químicas de solos degradados, bem como na atividade de microrganismos, considerando a possibilidade de um grande número de fontes de matéria orgânica (Reinert, 1998; Mendonça et al., 2001) citado por (Arato et al., 2003).

Os povos tradicionais da Amazônia possuem vasto conhecimento sobre o manejo dos SAFs e desenvolveram técnicas produtivas que garantiam e garantem o equilíbrio ecológico dos recursos naturais. Com a busca de alternativas de uso da terra na região, tem crescido a importância dos SAFs e a demanda por espécies de múltiplos usos. Nesse contexto, faz-se necessário conhecer experiências existentes na vivência dos povos tradicionais do Estado do Amazonas e como estas podem contribuir na elaboração de novas alternativas de produção, implementando novos elementos e técnicas que intensifiquem práticas sustentáveis e melhorem a qualidade de vida das populaçōes locais.

Os ribeirinhos, para efeito desta pesquisa, habitam o ecossistema de várzea. A apropriação desse espaço representa, segundo Noda et al. (2001:185), um mecanismo social de adaptação às características peculiares desse ambiente. Nesse sentido, este trabalho buscou compreender as diferentes formas de apropriação dos espaços e dos recursos naturais através dos sistemas agroflorestais, nos subsistemas roça, sítio e lagos, como alternativas sustentáveis para a população ribeirinha da Costa da Terra Nova, no município do Careiro da Várzea, Estado do Amazonas.

\section{MATERIAL E MÉTODOS}

Para a realização da pesquisa, foi utilizado o método de Estudo de Caso, tendo em vista as possibilidades de construção e de reconstrução focalizando, as dimensōes espaciais e temporais que estão claramente delimitadas e ligadas ao objeto de estudo. Segundo Yin (2001), esse método consiste no exame intensivo, tanto em amplitude quanto em profundidade, da unidade de estudo, empregando todas as técnicas disponíveis para o Estudo de Caso.

O enfoque desse estudo foi o conhecimento tradicional, o uso e o manejo dos ecossistemas de várzeas pelos agricultores familiares. A abordagem trabalhada foi a sistêmica apontada por Morin (2003), a qual busca entender não somente as relações todo-partes, como também entender o ambiente como uma macroorganização, uma organização tanto ecológica quanto social em processo contínuo de reorganização recorrente, através de interaçōes. O conceito de sistema, para o autor, consiste de três partes: (1) sistema - que exprime a unidade complexa e caráter fenomenal do todo, assim como o complexo das relações entre o todo e as partes; (2) interação - que exprime o conjunto das relações, ações e retroações que se efetuam e se tecem num sistema; (3) organização - que exprime o caráter constitutivo dessas interações - aquilo que forma, mantém, protege, regula, rege e regenera e que dá idéia de sistema a sua coluna vertebral.

Dentro dessa abordagem, o universo de estudo foi a população da Costa da Terra Nova, localizada no município do Careiro da Várzea, Estado do Amazonas, à margem direita do Rio Amazonas. Esse município possui área territorial formada por $80 \%$ de várzea, e sua base econômica encontra-se centrada nos setores agrícola, extrativista e pesqueiro. Cerca de $96 \%$ da população reside na zona rural, distribuída em 76 comunidades, entre as quais está a localidade da Costa da Terra Nova constituída de três comunidades: São Francisco, São José e Nossa Senhora da Conceição.

As técnicas empregadas, neste estudo, foram: aplicação de questionário, realização de entrevistas abertas, conversas informais, diário de campo e observação participativa. Primeiramente, foram contatadas as famílias de agricultores mais antigos indicados pelos presidentes das comunidades. Em seguida, foi realizada uma reunião para exposiçāo da natureza do trabalho aos comunitários que participaram da pesquisa. Após essa etapa, foi iniciada a aplicaçâo dos questionários, diários de campo e entrevistas abertas.

A aplicação de questionário e das entrevistas semiestruturadas foi realizada nas residências dos participantes da pesquisa, enquanto que as observações participativas nas unidades produtivas, no momento em que as atividades se desenvolviam. A pesquisa constou de uma intensidade amostral de $25 \%$ sobre o número total de estabelecimentos. As informações 
obtidas foram tabuladas e analisadas através de estatística descritiva conforme frequiências obtidas dos dados (Lima, 1994).

\section{RESULTADOS}

\section{DIVISÃO DO TRABALHO E CALENDÁRIO DE USO DA TERRA EM ÁREA DE VÁRZEA NO AMAZONAS}

A mão-de-obra predominantemente nas áreas de produção é a familiar, com média de 3,5 indivíduos maiores de 13 anos por propriedade, desenvolvendo diversas atividades. De acordo com dados obtidos as crianças (maiores de oito anos) "ajudam" nos horários em que estão fora da escola. Os trabalhos realizados na área de várzea atendem a um calendário de atividades (Figura 1) mediante a sazonalidade local.

$\mathrm{Na}$ época do preparo da área (agosto a fevereiro), há a participação de homens e mulheres nessa atividade. No plantio (setembro a fevereiro) e na colheita (outubro a maio), toda a família participa, inclusive até mesmo os agregados. Dos agricultores entrevistados, $14 \%$ contratam mão-de-obra externa à familiar para tais serviços. Mas, de maneira geral, os agricultores da Costa da Terra Nova não costumam contratar mão-de-obra.

De acordo com os agricultores de hortaliças, é quase impossível pagar diárias para outras pessoas, considerando que a renda obtida com a produção das hortas é mínima. Além disso, essa situação é mais agravante quando o próprio agricultor comercializa seus produtos, pois ele paga o transporte das hortaliças para serem comercializados em Manaus, mas precisamente na Feira Manaus Moderna.

Durante o período de inundações (março a julho), alguns agricultores continuam cultivando hortaliças em canteiros suspensos e os criadores de animais constroem instalaçôes suspensas para seus animais de médio porte (aves e suínos). Os criadores de gado transportam o rebanho para os pastos de terra firme ou constroem "marombas flutuantes" (currais flutuantes), onde confinam os animais até que os pastos fiquem novamente disponíveis na várzea.

\section{OS SISTEMAS AGROFLORESTAIS NA COSTA DA TERRA NOVA}

Os sistemas agroflorestais estudados na Costa da Terra Nova são constituídos por três subsistemas: roça, quintal e lago, de suma importância para a população local. Os SAFs estudados abrangem as três categorias silviagrícolas, silvipastoris e agrossilvipastoris. A categoria silviagrícola é caracterizada pela presença de árvores de porte alto e médio, como seringueiras (Hevea brasiliensis, andiroba (Carapa guianensis Aubl.), manga (Mangifera indica), cupuaçu (Theobroma grandiflorum (Willd. ex Spreng.) Schum), jambo (Syzygium malaccense), entre outras, com árvores arbustivas, como, por exemplo, algumas medicinais, malvarisco - Plectranthus amboinicus (Lour.) Spreng , algodão-roxo etc., com cultivos de ciclo curto: mandioca (Manihot esculenta Crantz), milho (Zea mays), feijāo, hortaliças (cheiro verde - Coriandrum sativum L, chicória (Cichorium endivia L.).

Os sistemas agroflorestais locais estão também dentro da categoria silvipastoris, caracterizados pela presença de árvores de diversos estratos arbóreos com plantas forrageiras e criação de gado. Outra categoria identificada é a agrossilvipastoril, caracterizada pelo consórcio silviagrícola e a criação e manejo de animais domésticos (aves e suínos) e animais silvestres, tais como capivara (Hydrochoerus hydrochoeris), quelônios, entre eles, a tartaruga da Amazônia (Podcnemus expansa).

Nas áreas de várzea da Amazônia, o lago é um componente dos SAFs nativos manejados devido a sua importância e sua função na sustentabilidade do sistema de produção dos povos tradicionais. O manejo dos $\mathrm{SAF}$ s pela população local, envolvendo os lagos, é o fator que diferencia dos SAFs de outras regiōes do País. Isso porque, esse componente faz parte

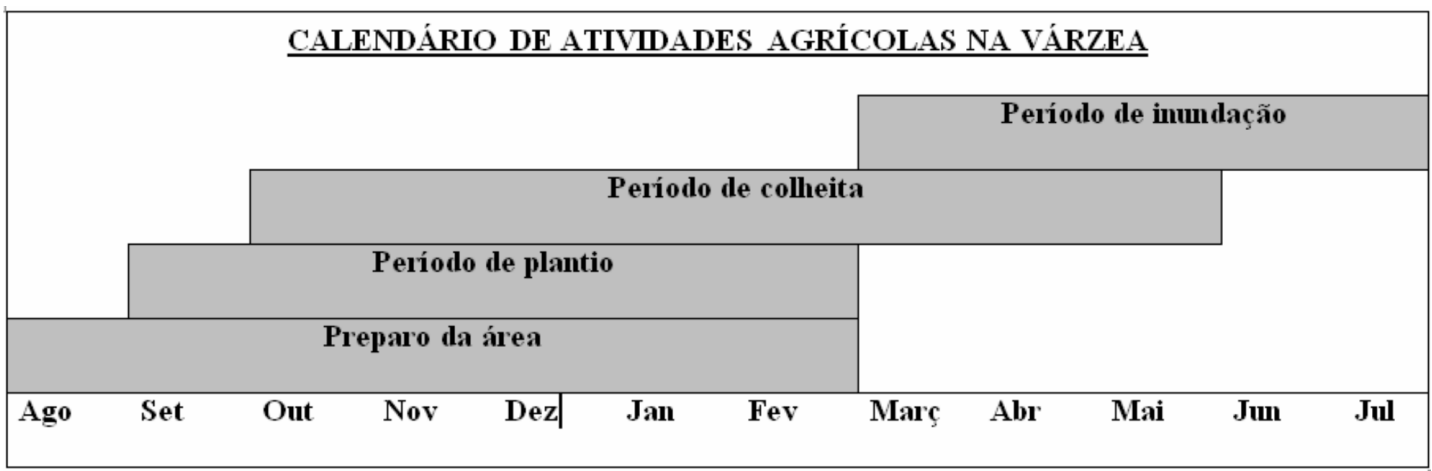

Figura 1 - Distribuição das atividades agrícolas e período de inundação das áreas agricultáveis na várzea da localidade da Costa da Terra Nova, Careiro da Várzea/AM. 
da área de produção dos agricultores da várzea. Os SAFs da Costa da Terra Nova, em sua maioria, são as margens dos rios e lagos. Os ribeirinhos habitantes desses ambientes, quando manejam seus SAFs, realizam, simultaneamente, o manejo das matas ciliares nas margens desses aqǘferos, possibilitando a conservação destes e a reprodutibilidade das espécies existentes. $\mathrm{O}$ resultado de tal manejo é a diversidade e aumento de pescado, principal fonte de proteína para a população local. Nesse sentido, o lago é um importante subsistema dos SAFs nas áreas de várzea, pois, junto com os subsistemas roça, quintal ou sítio, são responsáveis pela dinâmica da sustentabilidade do ambiente e dos povos tradicionais envolvidos.

Os caboclo-ribeirinhos desenvolveram técnicas de manejo que foram repassadas através de sua cultura. Essas técnicas são adaptadas para cada fase sazonal (vazante, cheia, seca e enchente.) dentro do meio físico amazônico. A economia local está ligada a uma variedade de atividades de subsistência (agricultura, caça, pesca e extrativismo) dentro dos subsistemas roças, quintal e lago que é vital para sustentabilidade dos povos amazônicos que vivem na floresta.

\section{SUBSISTEMA QUINTAL OU SÍTIO}

O quintal ou sítio florestal é o local onde é cultivada uma ampla variedade de plantas perenes e anuais em torno da casa do agricultor e tem como função garantir a manutenção da família. O quintal ou sítio florestal é de suma importância para a população local, pois complementa a produção obtida em outras áreas de produção da propriedade, como a roça, a criação de animais, a floresta e as capoeiras melhoradas, além de servir como área de lazer para a família. Viana et al. (1996) relatam que o quintal florestal é utilizado para obter alimentos ricos em proteínas, vitaminas e sais minerais. Normalmente, o quintal ou sítio florestal é utilizado para assegurar um

Tabela 1 - Principais espécies frutíferas com expressão econômica cultivadas nos quintais florestais, nas comunidades São Francisco, São José e Nossa Senhora da Conceição, localidade Costa da Terra, Careiro da Várzea-AM.

\begin{tabular}{lllc}
\hline Espécies & Nome científico & \multicolumn{2}{l}{ Finalidade } \\
\hline Açaí & Euterpe oleracea Mart. & A & V \\
Bacuri & Platonia insignis Mart. & A & \\
Banana & Musa spp. & A & V \\
Cacau & Theobroma cacao L. & A & V \\
Caju & Anacardium occidentale L. & A & \\
Coco & Cocos nucifera L. & A & V \\
Cupuaçu & Theobroma grandiflorum (Willd. Ex & A & V \\
\cline { 2 - 2 } & Spreng.) Schum & Citrus limon (Linn.) Burn & \\
Manga & Magifera indica L. & A & V \\
\hline
\end{tabular}

A - AUTOCONSUMO; V - VENDA. fluxo pequeno e contínuo de produtos complementares para subsistência e/ou produzir excedente para a venda.

Foi observado, na área pesquisada, que os quintais ou sítios florestais têm um papel importantíssimo para os cabocloribeirinhos da Costa da Terra Nova, pois fornecem produtos tanto para a subsistência quanto para a comercialização e servem também como oficina para a elaboração de outros trabalhos como, por exemplo, a construção de canoas, móveis, apetrechos de pesca, entre outros trabalhos.

Nos quintais ou sítios florestais da localidade da Costa da Terra Nova, são cultivadas variedades de plantas frutíferas e medicinais. As principais espécies frutíferas cultivadas, tanto para subsistência quanto para comercialização, podem ser visualizadas abaixo (Tabela 1 ).

Todas as unidades familiares pesquisadas apresentaram cultivo de plantas medicinais nos quintais ou sítios florestais. Isso se deve à importância dessas plantas na cura e na prevenção de doenças como gripe, dor de cabeça, gastrite, inflamação no ouvido, entre outras. Os conhecimentos sobre a utilização dessas plantas são transmitidos de geração a geração através dos pais, avós, bisavós, vizinhos, rezadeiras ou curandeiros da localidade.

$\mathrm{Na}$ Figura 2, estão representados os percentuais das principais espécies medicinais utilizadas nos quintais, na localidade da Costa da Terra Nova. Das diversas espécies cultivadas, as mais encontradas foram mastruz (Chenopodium ambrosioides L.), hortelã (Mentha piperita L.) e boldo (Chenopodium ambrosioides L.), com destaque para o mastruz, que é utilizado tanto para o consumo da família quanto para a comercialização. Os processos de trabalhos relacionados ao cultivo das plantas medicinais estão divididos da seguinte forma: quem participa no cultivo são as mulheres e as crianças,

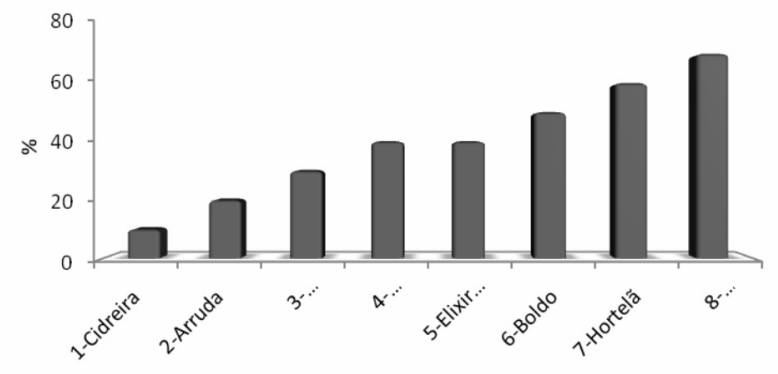

1- Melissa officinalis L.; 2-Ruta graveolens; 3-Cymbopogon citratus (D.C.) Stapf; 4- Alternantera sp. 5- Ocimum selloi ; 6- Coleus barbatus; 7 - Mentha sp.; 8Chenopodium ambrosioide.

Figura 2 - Principais espécies medicinais cultivadas nos quintais para 0 consumo na comunidade São Francisco, São José e Nossa Senhora da Conceição, Careiro da Várzea-AM. 
mas, na comercialização do mastruz, tanto os homens quanto as mulheres participam da negociação com os atravessadores ou realizam a venda direta na feira Manaus Moderna.

As espécies cultivadas nos quintais ou sítio florestais são comercializadas em pouca quantidade e não são contabilizadas pelos agricultores devido à variabilidade na quantidade, relacionada à área cultivada em cada ano. $\mathrm{O}$ depoimento de um dos agricultores expressa essa racionalidade: "... agente vende por quantidade, mas não tem quantidade certa".

As principais espécies comercializadas são: açaí (Eutherpe oleracea Mart.), banana (Musa spp. L), cacau (Theobroma cacao L.), coco (Cocos nucifera L.), manga (Mangifera indica L.) e mastruz (Chenopodium ambrosioides L.). Destas, as que são comercializadas são a manga e o mastruz. Em relação à cultura da manga, foi constatado que não existem grandes plantios que justifiquem um estudo da cadeia produtiva desse produto que tenha como unidade analítica os quintais pesquisados.

\section{PRODUÇÃO DE ANIMAIS NOS QUINTAIS FLORESTAIS}

A produção animal na Comunidade São Francisco é, sobretudo, para subsistência, sendo as aves e suínos os principais. A alimentação desses animais é composta por restos de comida, ração, milho, insetos e frutas que caem das árvores no quintal. Quanto às instalaçôes utilizadas para a criação, há mudanças de acordo com a sazonalidade. No período da seca, os animais são criados de forma semi-extensiva; já durante a cheia dos rios, esses animais, necessariamente, são alocados em instalações suspensas, regionalmente denominadas de marombas. Estas instalações mitigam a mortalidade dos animais. Nesse sentido, a subida das águas representa um período em que os agricultores vendem na comunidade ou passam a consumir mais as proteínas oriundas de suas criaçóes. Outro aspecto importante a ser citado é o a necessidade do autoconsumo desses animais e a escassez de outra fonte de proteína animal - o pescado (a mais importante para os povos amazônicos).

Os animais de grande porte criados na localidade são os bovinos e os eqüinos. O principal alimento desses animais é o capim, que pode ser natural ou plantado. O capim utilizado pelos criadores é o braquiária (Brachearia decumbens), que se tem adaptado ao tipo de solo da localidade. As áreas de pasto são cercadas com arame para que os animais não pisoteiem as plantaçōes dos agricultores familiares ou são criados em locais mais distantes das áreas de plantação.

O gado bovino é criado para o consumo e como fonte de renda, de modo que senso predominante é o de funcionar como "poupança”. Na época da cheia, quando não há possibilidade da construção de marombas, a maioria é levada para áreas alugadas na terra firme, acarretando gastos adicionais aos agricultores, que pagam frete com o deslocamento desses animais até o novo destino.

\section{SUBSISTEMA ROÇA}

A roça ou roçado é o local onde, geralmente, são cultivadas espécies anuais durante períodos específicos (normalmente dois ciclos, dependendo da qualidade do solo); posteriormente, são deixadas em descanso, para a recuperação da fertilidade e eliminação das plantas invasoras no solo (Noda et al., 2002). Essa técnica conhecida, como pousio, permite que os nutrientes disponíveis do solo sejam recuperados. No entanto, na área pesquisada, o pousio dos solos de várzea ocorre durante o tempo de inundação. Após esse processo, aparecem as praias, e é neste período (agosto a março) que os agricultores realizam a limpeza da área e o cultivo das suas culturas.

De acordo com dados obtidos, cerca de $48 \%$ dos agricultores, no final do ciclo da cultura, antes do período de inundação, realizam uma limpeza na área. Segundo esses agricultores, essa prática faz com que aumente o tempo de produção, pois, quando as praias retornam, há a redução do trabalho da limpeza do terreno, havendo, dessa forma, um aumento no tempo de manejo para algumas culturas.

$\mathrm{Na}$ roça, o processo de limpeza da área de trabalho se inicia nos meses de julho e agosto, logo após a descida das águas. O preparo da área é executado, principalmente, pelos homens adultos e jovens em virtude de essa atividade exigir força física, no entanto, em casos de extrema necessidade, as mulheres participam parcialmente. Os processos de trabalho nas roças, realizados em várzea alta de mata primária, envolvem a derruba da capoeira, a queima, seguida de encoivaramento e requeima.

Nas roças, durante a vazante (setembro a fevereiro), são cultivados hortaliças, feijão, milho, fibras, melancia, quiabo e outras culturas de ciclo curto. Estas são geralmente cultivadas em leiras e em época de cheia (março a julho) e passam a ser cultivadas em jiraus ou canteiros suspensos. As principais culturas nessas instalaçôes são: chicória, cebolinha, coentro e couve, pois exigem menor espaço para se desenvolverem. De acordo com Fraxe (2000), a predominância do cultivo de hortaliças convencionais talvez seja a característica mais marcante dos atuais sistemas agrícolas de várzea, se comparados aos sistemas de terra firme, no Estado do Amazonas.

Grande parte das hortaliças produzida na Costa da Terra Nova é comercializada, sendo apenas uma parcela mínima destinada ao consumo familiar. As principais são as que formam o cheiro-verde (chicória, cebolinha e o coentro) usado como condimento, principalmente, para o preparo do pescado. Na Figura 3, estão relacionadas os principais produtos cultivados nas roças para fins de comercialização e subsistência, merecendo destaque a chicória e o quiabo, que conferem a maior produtividade, por serem bem adaptados às condiçôes locais. A produtividade média, bem como o número de ciclo das principais espécies para comercialização, podem ser observados na Tabela 2. 
Fraxe (2000), em pesquisas realizadas na Costa da Terra Nova, faz uma comparação com outras áreas do Estado do Amazonas, como Coari, Parintins, Manacapuru, Iranduba, Manaquiri, Tefé e Itacoatiara e constata que o índice de frequiência de produção de hortaliças, principalmente do quiabo e da chicória, é maior nessa localidade. Isto se deve, principalmente, pela proximidade do centro urbano e por essas culturas estarem intrinsecamente ligadas ao habitus estruturado dessa população. A mandioca é utilizada essencialmente para a produção de farinha, é comercializada apenas em pequena quantidade, a qual é um componente importante e indispensável na dieta alimentar dos cabocloribeirinhos.

Cerca de $70 \%$ dos agricultores entrevistados relataram que cultivam hortaliças na localidade aproximadamente há 20 anos e que essas culturas são responsáveis pela renda familiar.

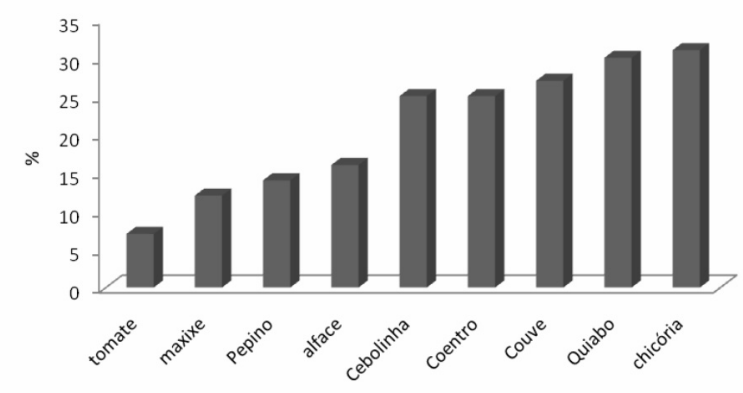

Figura 3 - Freqüência das principais culturas cultivadas nas roças dos agricultores da Costa da Terra Nova, Careiro da várzea/AM. Fonte: Pesquisa de campo, 2006
Durante o ciclo de cultivo das hortaliças, seja no período de seca, seja na cheia, $70 \%$ dos agricultores retiram semente ou parte propagativa como, por exemplo, raiz da cebolinha para o próximo ciclo de cultivo. $30 \%$ deles conseguem essas sementes de outras formas, comprando ou com vizinhos.

A forma de cultivo das hortaliças praticada pelos agricultores é bastante simples. Utilizam como sementeiras as leiras, que, para algumas culturas, podem ser definitivas, copinhos ou jiraus, sendo estes últimos o mais utilizado na época da cheia. $\mathrm{O}$ transplantio das mudas para o local definitivo varia de acordo com as espécies, sendo que as mais comumente cultivadas nessa localidade são as que dão retorno financeiro imediato e as quais ocupam o solo por pouco período de tempo, característica de espécies vegetais utilizadas nas áreas de várzea.

\section{SUBSISTEMA LAGO}

A principal atividade de extrativismo animal na área estudada é a pesca, sendo esta atividade, depois da agricultura, a que consome maior tempo de trabalho do agricultor. A pesca nas comunidades da Costa da Terra Nova é praticada tanto para o autoconsumo quanto para a comercialização, principalmente na época da cheia. A comunidade é considerada comumente pesqueira entre as três da Costa da Terra Nova é a São José.

Um dos principais locais utilizados para a pesca é o lago Joanico, pertencente às três comunidades. Essas regiōes lacustres são comumente preferidas pelos moradores em suas proximidades, pois, nesse ambiente, a captura dos peixes é facilitada pela alta densidade em que se encontram, particularmente durante a seca, quando o ambiente se torna fechado. Devido à fragilidade das embarcaçôes freqüentemente

Tabela 2 - Área média (ha), produção média (kg/ha), ciclo da cultura (dias), número de ciclo por ano das principais espécies cultivadas nas roças com finalidade comercial e participação de agricultores na atividade (\%), nas comunidades de Terra Nova Careiro da Várzea/AM.

\begin{tabular}{|c|c|c|c|c|c|}
\hline Culturas & Área Média/ (ha) & $\begin{array}{l}\text { Produção média/ } \\
\text { agricultores }\end{array}$ & $\begin{array}{c}\text { Ciclo da } \\
\text { Cultura } \\
\end{array}$ & $\begin{array}{l}\mathrm{N}^{0} \text { ciclo/ } \\
\text { ano }\end{array}$ & $\begin{array}{l}\% \\
\text { Agricultores }\end{array}$ \\
\hline Chicória & 0,500 & 20 a $60 \mathrm{Kg}$ & 70 dias & 3 ciclos & 15,5 \\
\hline Cebolinha & 0,003 & 20 a $100 \mathrm{Kg}$ & 55 dias & 4 ciclos & 12,5 \\
\hline Coentro & 0,500 & 30 a $120 \mathrm{Kg}$ & 70 dias & 3 ciclos & 12,5 \\
\hline Alface & 0,003 & 75 a $120 \mathrm{Kg}$ & 50 dias & 4 ciclos & 08 \\
\hline Couve & 500 & 20 a $60 \mathrm{Kg}$ & 60 dias & 3 ciclos & 13,5 \\
\hline Pimentão & 0,500 & 30 a $40 \mathrm{Kg}$ & 75 dias & 3 ciclos & 05 \\
\hline Pepino & 0,500 & 10 a $50 \mathrm{Kg}$ & 60 dias & 3 ciclos & 07 \\
\hline Quiabo & 0,500 & 100 a $150 \mathrm{Kg}$ & 90 dias & 2 ciclos & 14 \\
\hline Mandioca & 0,004 & 60 a $240 \mathrm{Kg}$ & 100 dias & 2 ciclos & 07 \\
\hline Maxixe & 0,500 & 100 a $150 \mathrm{Kg}$ & 80 dias & 3 ciclos & 02 \\
\hline $\begin{array}{l}\text { Pimenta de } \\
\text { Cheiro }\end{array}$ & 0,500 & 20 a $10 \mathrm{Kg}$ & 110 dias & 2 ciclos & 02 \\
\hline
\end{tabular}


utilizadas na pescaria da região, os pescadores preferem as águas calmas do lago para atividade pesqueira (Cerdeira $e t$ al., 1997).

De acordo com Garcez (2000), a preferência pelo lago também se deve ao fato de os pescadores considerarem que os peixes desses ambientes são mais palatáveis.

$\mathrm{Na}$ área estudada, foi verificado certo conflito entre os moradores com relação ao lago Joanico, por se tratar de uma área coletiva. De acordo com Souza (2003), os lagos de várzea são os principais locais onde ocorrem conflitos entre usuários dos recursos pesqueiros.

Os moradores locais relataram que os pescadores da comunidade São José não respeitam o acordo de pesca na época do defeso, que compreende o período de primeiro de agosto a primeiro de novembro. A atitude da comunidade de restringir ao uso de pesqueiros é uma prática relativamente comum. Ela é desenvolvida em respostas ao aumento na pressão sobre os estoques. Geralmente, essa ação é comandada pela comunidade ribeirinha, caracterizada por ser um grupo social que, conscientemente, assume a responsabilidade pelo manejo sustentável do estoque de peixe (Batista et al., 2000).

Diante da importância dada à sustentabilidade dos estoques pesqueiros na região, foi constatado que a economia da comunidade é fortemente centrada na comercialização do pescado, depois da produção de hortaliças.

A intensidade de uso e a necessidade contínua dos recursos pesqueiros para geração de renda levam a um conflito entre os pescadores comerciais da Comunidade São José e os que o utilizam pescado principalmente para o autoconsumo. Segundo Hartmann (1990) esses conflitos de pesca em águas interiores da Amazônia são comuns.

Nessa localidade, a pesca é realizada durante todo o ano, e, de acordo com dados coletados, intensifica-se de maneira geral nas três comunidades (São Francisco, São José e Nossa Senhora da Conceição), durante o período da cheia. Isso se dá devido à ausência de terra para a produção e a necessidade de alimento e produto para comercializar.

A venda do pescado é utilizada para complementar a renda obtida a partir de outras atividades como: agricultura, extração de madeira ou criação de animais (Barthem et al., 1997), ajudando a suprir os agricultores de bens que não podem ser produzidos por eles durante o período de inundação de suas áreas produtivas.

$\mathrm{Na}$ época da seca, a pesca é mais produtiva, ou seja, os cardumes estão concentrados nos lagos perenes que tiveram seus espelhos d'água reduzidos, sendo a produção comercializada na feira da Manaus Moderna e na própria localidade, tendo, como principal consumidor, os turistas que visitam a região.
O pescado, além de ser fonte de renda e alimento para as famílias, é o que gera subproduto para o artesanato local. Um exemplo disso é a escama do pirarucu, utilizada para a produção de adereços, tais como colares, pulseiras, brincos, entre outros. Dessa forma, na região estudada, a intensidade no desempenho da atividade pesqueira varia em função do regime de subida e de descida das águas. Das comunidades pesquisadas, a única que agrega parte significativa de sua renda à pesca é a comunidade São José, sendo a única que recebe turistas.

O extrativismo pesqueiro é realizado pela força familiar (pai, mãe e filhos). Os principais apetrechos utilizados na captura do pescado tanto para subsistência como para comercialização são: caniço, malhadeira, tarrafa, espinhel, flecha, arpão e zagaia. A preferência pelos dois primeiros apetrechos corrobora com o observado por Petrere (1992) para pescarias artesanais de subsistência na captura dos peixes. $\mathrm{O}$ destaque da malhadeira, entre os apetrechos, é uma situação comum na pesca efetuada na região Amazônica, sendo, em muitas regiōes, freqüentemente utilizada ao longo de todo o ano (Garcez, 2000; Batista et al., 2000). Esse apetrecho também é recomendado para locais de pouca correnteza como o lago. Entretanto, em lagos regulamentados por acordos de pesca, não é permitido o uso de malhadeira, pois esta é considerada a principal causa de pressão excessiva sobre os recursos aquáticos. Para Macgrath et. al. (1994), restringir o uso de malhadeira é considerado a forma mais efetiva de limitar o tamanho da captura.

A pesca feita pelos caboclo-ribeirinhos é realizada usualmente a bordo de pequenas embarcações (no caso da área de estudo, canoas a remo e canoas movidas a motorrabeta), que permitem alcançar apenas pequenas distâncias (Fernandez-baca, 1998; Cerdeira et al., 2000).

As espécies capturadas são, em sua maioria, Characiformes e Perciformes, o que reflete a preferência por peixes de "escama" em detrimento dos Siluriformes, que são destinados mais para venda do que para o consumo local em virtude dos tabus alimentares existentes na região Amazônica (Smith, 1979; Garcez, 2000). As principais espécies capturadas para o consumo e para a comercialização são listadadas na Figura 4, abaixo:

As práticas dos caboclo-ribeirinhos da Costa da Terra Nova são reguladas pelas experiências acumuladas, inseridas no contexto direto com o seu próprio sistema social. De acordo com McGrath et al. (1994), a utilização dos conhecimentos, experiências e iniciativas das comunidades ribeirinhas sobre o estabelecimento de reserva de lago pode ser considerada uma verdadeira alternativa para gerenciamento pesqueiro local, e o lago pode ser uma unidade de manejo viável para proteção de várias espécies de peixe economicamente importantes. 


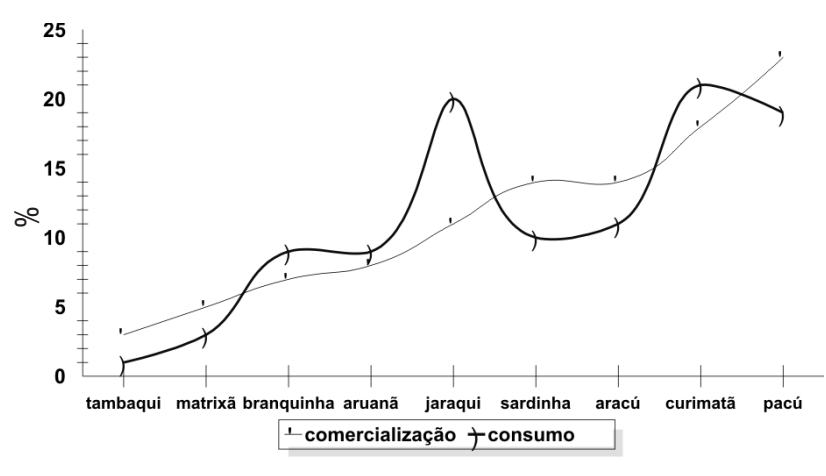

Figura 4- Freqüência de peixes capturados para consumo e venda pelos agricultores familiares da Costa da Terra Nova - AM.

De acordo com Pereira (2002), o manejo local participativo e a formalização de jure de regimes de propriedade coletiva representam uma alternativa ao modelo convencional, baseado em seqüestro social de grandes territórios para o estabelecimento de unidades de conservação geridos exclusivamente pelo poder público. Uma característica essencial e diferenciada dessas iniciativas de gestão local de recurso natural é que elas buscam integrar e potencializar açôes que objetivem a conservação da natureza e o desenvolvimento social das populaçōes, simultaneamente.

As intervençôes que impedem a entrada de outros usuários nos ambientes pesqueiros têm, na territorialidade, o seu elemento-chave (Hartmann, 1990). De acordo Mcgrath et al., 1994, o controle do lago se dá pela extensão da posse dos membros da comunidade que moram nas terras que o contornam, na tentativa de garantir a sustentabilidade dos recursos, que são sua base de subsistência. Ainda segundo esses autores, embora a terra ao redor do lago tenha proprietários individuais, o lago é considerado como área "comum". Por essa razão, o manejo é coletivo e em geral, envolvendo todos os moradores da comunidade.

Os problemas entre os membros da comunidade e os pescadores comerciais ocorrem especialmente no período de cheia, quando, além da facilidade de entrada no lago, estes últimos são impelidos de pescar nesse ambiente em busca de estoques alternativos, devido à queda da produtividade e ao aumento da dificuldade das pescarias na calha do rio (Ruffino \& Isaac, 1999).

Tais características da economia indicam sua natureza e sua inserção em esferas econômicas mais gerais. Assim, o espaço (ou espaços) produtivo (construído de terra e meio aquático) não se define simplesmente por sua potencialidade biológica, mas por suas implicaçôes históricas que dinamizam o espaço natural para um espaço socioeconômico, tornando-o socialmente utilizável.

\section{COMERCIALIZAÇÃO}

Os produtos oriundos dos SAFs são comercializados pelos agricultores para os agentes de comercialização (regatão, patrão, marreteiro e marreteiro-feirante) ou são levados pelos próprios agricultores para serem comercializado em Manaus na feira Manaus Moderna. O principal produto utilizado na comercialização são as hortaliças, nas comunidades São Francisco e Nossa Senhora da Conceição. Já na Comunidade São José, é o pescado, comercializado no Porto da CEASA e na feira Manaus Moderna. O período de venda das hortaliças varia muito, segundo dados obtidos com os moradores do local, pois a produção depende de uma série de fatores. Em primeiro lugar, cada agricultor possui um período de plantio próprio. Muitos plantam o ano todo; outros apenas nos últimos meses do ano.

Apesar da relativa proximidade com a capital, os agricultores pagam caro pelo transporte de suas caixas e maços de verduras. A passagem para a cidade de Manaus custa $\mathrm{R} \$$ 20,00 (ida e volta); cada caixa transportada custa de dois a três reais. Além do dinheiro gasto com o transporte, os agricultores precisam pagar os carregadores para transportar suas mercadorias do barco até a feira Manaus Moderna.

Outra desvantagem relatada pelos agricultores é a falta de um local adequado para vender seus produtos (hortaliças). Esses ribeirinhos feirantes são chamados de "os sem-terra" porque é assim que eles se denominam por não possuírem box na feira Manaus Moderna. Assim sendo, vendem seus produtos em caixas de madeiras na frente dos banheiros, no corredor ou na entrada da feira. Segundo relatos dos ribeirinhos feirantes, devido à falta de lugar adequado para vender seus produtos, são obrigados a comercializar, na maioria das vezes, com preço $50 \%$ menor em relação aos feirantes que vendem em boxes. Os produtos levados pelos ribeirinhos feirantes são vendidos para o consumidor final ou são comercializados para os feirantes intermediários de outras feiras, que compram o produto mais barato e em grande quantidade. Alguns agricultores chegaram a relatar que, algumas vezes, eles voltam com parte ou toda a produção da semana.

\section{CONSIDERAÇÕES FINAIS}

Os caboclos-ribeirinhos na área de várzea na localidade da Costa da Terra Nova utilizam sistema de produção com características semelhante às das demais localidades de várzea na Amazônia, localizadas próximo à capital do Estado, pois sofrem influência das enchentes e da proximidade do centro urbano. A estratégia de produção, nessa área, se dá através do conhecimento da população local, adquirido através da convivência diária neste ecossistema. 
No período da cheia, para garantir a sobrevivência da família e a continuidade da sua produção, os agricultores familiares constroem pequenos jiraus para o plantio de hortaliças e plantas medicinais e também plantam espécies resistentes às cheias em seus quintais. Nesse período, os ribeirinhos reduzem suas criações de animais (através do consumo ou venda), deixando apenas algumas matrizes para garantir a continuidade da suas criaçôes. Esses animais ficam confinados em instalações suspensas (maromba) ou flutuantes.

Devido ao curto período em que os solos ficam aptos ao uso agrícola, os agricultores locais cultivam, nas suas roças, espécies de ciclo curto, que são utilizadas tanto para o autoconsumo quanto para a comercialização, realizada pelos agentes de comercialização ou pelos próprios agricultores na feira Manaus Moderna.

Em virtude de grande parte dos agricultores da Costa da Terra Nova cultivar hortaliças, é necessário capacitação técnica para melhorar a qualidade da produção, com orientação para o uso racional de fertilizantes e defensivos químicos, bem como instrução sobre a aplicação correta de adubos orgânicos e químicos; intensificação das atividades de assistência técnica e extensão rural para melhor desempenho das atividades produtivas; minicursos de administração rural direcionado aos agricultores de hortaliças; cursos de lideranças para promover a organização social e a criação de uma cooperativa de horticultores e implementação de políticas públicas, visando reduzir ou extinguir os agentes de comercialização, além da construção de um local por parte das autoridades competentes na feira Manaus Moderna para os ribeirinhosfeirantes poderem expor e comercializar seus produtos e, finalmente, uma parceria entre associaçôes de agricultores, prefeituras, instituições de pesquisa, ensino e extensão. A articulação desses atores é fundamental para viabilizar uma proposta de política pública para o desenvolvimento socioeconômico sustentável dessa localidade e sugeri-la para outros assentados no ecossistema de várzea.

\section{BIBLIOGRAFIA CITADA}

Arato, H.D. ; Martins, S.V. ; Ferrari, S.H. 2003. Produção e decomposição de serapilheira em um sistema agroflorestal implantado para recuperação de área degradada em Viçosa-MG. Rev. Árvore, 27(5): p. 715-721.

Barthem, R.B.; Petrere JR., M; ISAAC, V.J.; Ribeiro, M.C.L.B.; Mcgrath, D.G.; Vieira, I.J.A.; Valderama-barco, M.A.A. 1997. Pesca na Amazônia: problemas e perspectivas para o seu manejo. In: Valadares-Pádua, C. \& Bodmer, R. E. [eds.] Manejo e Conservação da Vida Silvestre no Brasil. MCT-CNPq, Sociedade Civil Mamirauá. p.173-184.

Batista, V.S.; Freitas, C.E.C.F.; Silva, A.J.I.; Freire-brasil, D. 2000. The fishing activity of the river people in the floodplain of the Central Amazon. In: Junk, W. J.; Ohly, J. J.; Piedade, M.T.F;
Soares, M.G.M. The Central Amazon Floodplain: Actual use and options for a sustainable management. Backhuys Publisherrs, Leiden, The Netherlands. p. 417-431.

Cerdeira, R.G.P.; Ruffino, M.L.; Isaac, V.J. 1997. Consumo de pescado e outros alimentos nas comunidades ribeirinhas do Lago Grande de Monte Alegre. Acta Amazonica, 27(3): 213-227.

Chizzotti, A. 2003. Pesquisa em ciências humanas e sociais. 6a ed. São Paulo: Cortez. 200pp.

Daniel, O.; Couto, L.; Garcia, R.; Passos, C.A.M. 1999. Proposta para padronização da terminologia empregada em sistemas agroflorestais no brasil. Revista Árvore, 23(3): 367-370.

Embrapa-CPAA. 1992. Encontro Brasileiro de Economia e Planejamento Florestal. 2v. Curitiba: Anais. Colombo.

Fernandez-baca, J. 1998. Amazonian Fisheries: Socio Economic Issues and Management Implications. Environmental economics programme. Discusssion Paper. DP 98-02. 38pp.

Fraxe, T.J.P. 2000. Homens anfibios: etnografia de um campesinato das águas. São Paulo Annablume; Fortaleza: Secretaria de Desporto do Governo do Estado do Ceará. 192pp.

Garcez, D.S. 2000. A pesca de ribeirinhos em ambientes de várzea de uso comum, Baixo Solimões, Amazônia Central. Dissertação de mestrado apresentada ao Programa de Pós-Graduação em Biologia Tropical e Recursos Naturais. INPA/UA. 89pp.

Hartmann, W.D. 1990. Por uma co-administração de recursos pesqueiros em águas interiores da Amazônia: o caso das comunidades ribeirinhas e pesqueiras do Lago Grande de Monte Alegre. In: Populaçôes, rios e mares da Amazônia. IV. Encontro de Ciências sociais e o mar no Brasil. Belém. p.157-168.

Mcgrath, D.G.; Castro, F.; Futemma, C. 1994. Reserva de lago e o manejo comunitário da pesca no Baixo Amazonas: uma avaliação preliminar. In: D’Incao, M. A. S. Silveira, I. M. (eds.) Amazônia e a crise de modernização. Publi. Museu Paraense Emilio Goeldi, Belém. p. 399-402.

Noda, S.N.; Noda, H.; Martins, L.L.U. 2001. Utilização e apropriação das terras por agricultura familiar amazonense de várzea. In: Antônio Carlos Diegues e André de Castro C. Moreira (Org.). Espaços e recursos naturais de uso comum. São Paulo: NUPAUB-USP. 294pp.

Noda, S; Noda, H; Martins, A.L.U. 2002. Papel do processo produtivo tradicional na conservação dos recursos genéticos vegetais. In: RIVAS A.; FREITAS, C.E. de C. (Org). Amazônia uma perspectiva interdisciplinar. Manaus: Editora da Universidade do Amazonas, 271pp.

Pereira, C. 2002. Agricultura familiar esperança sustentável. Instituto de Pesquisa da Ambiental da Amazônia (IPAAM), Belém. 64pp.

Petrere JR., M. 1992. As comunidades humanas ribeirinhas da Amazônia e suas transformaçôes sociais. In: Diegues, A. C. (ed.). Populaçôes humanas, rios e mares da Amazônia. Anais do IV Encontro de Ciências Sociais e o Mar no Brasil. p. 31-68.

Ruffino, M.L.; ISAAC, V.J. 1999. Dinâmica Populacional de Surubim-tigre, Pseudoplatystoma tigrinum (Valenciennes, 1840) no Médio Amazonas (Siluriformes, Pimelodidae). Acta Amazonica, 29: 463-476. 
Smith, N.J.H. 1979. A pesca no rio Amazonas. Conselho Nacional de Desenvolvimento Científico e Tecnológico - CNPq / INPA. Manaus - AM. 154pp.

Souza. L. 2003. Sustentabilidade ecológica e econômica da pesca de subsistência na Amazônia Central. Dissertação de Mestrado, Instituto Nacional de Pesquisa da Amazônia/Universidade Federal do Amazonas, Manaus, Amazonas. 150pp.

Viana, V.M.; Dubois, J.C.L.; Anderson, A.B. 1996. Manual Agroflorestal para a Amazônia. Vol. 1, Rebraf/Fundação Ford, Rio de Janeiro. 228pp.

Yin, R.K. 2001. Estudo de caso: planejamento e métodos. 2. ed. Porto Alegre: Bookman, 205pp.

Recebido em 05/03/2007

Aceito em 19/07/2008 